\title{
The Impact of COVID-19 on Urology Practice in Oman
}

$$
\text { تأثير كوفيد-19 على ممارسة جراحة المسالك البولية في عُمان }
$$

\section{Dear Editor,}

There have been many changes in the healthcare sector due to the current COVID-19 pandemic. In the future, we will have to deal with the post-COVID-19 era. The aim of this article is to highlight the impact of COVID-19 on urology practice in Oman in relation to local and international responses as well as emphasised the importance of telemedicine in the continuity of care for our patients and discuss how we can be better prepared for future pandemics.

The COVID-19 disease is caused by the virus called SARS Coronavirus-2 (SARS CoV-2). ${ }^{1}$ Up to October 25, there were 42,512,186 confirmed cases of COVID-19 worldwide including 1,147,301 deaths. In Oman, there were 111,837 confirmed cases of COVID-19 with 1,147 deaths. ${ }^{2}$

\section{INTERNATIONAL CHANGES}

The first impact on urology education that occurred was the postponement of the $35^{\text {th }}$ Annual Congress of the European Association of Urology (EAU), which was to be held in Amsterdam from 20 March to 17 July, 2020. This was followed by the announcement of converting the EAU20 Congress (17-19 July) to a virtual event. All international urological bodies have released guidelines to direct urologists on how to deal with the pandemic and how to prioritise urological procedures. The EAU Guidelines Office Rapid Reaction Group released the updated guidelines only two weeks after the release of the official guidelines at the end of March 2020. ${ }^{3}$ The main aim was to aid clinicians in making management decisions that reflected on local circumstances by the introduction of a chart that divided priorities into different levels [Table 1]. ${ }^{4}$

Table 1: Levels of priority as defined by the European Association of Urology Guidelines Office Rapid Reaction Group ${ }^{4}$

$\begin{array}{lcccc}\text { Priority Category } & \text { Low Priority } & \text { Intermediate Priority } & \text { High Priority } & \text { Emergency } \\ \text { Definition } & \begin{array}{c}\text { Clinical harm very } \\ \text { unlikely if postponed } \\ \text { six months }\end{array} & \begin{array}{c}\text { Clinical harm possible } \\ \text { if postponed 3-4 }\end{array} & \begin{array}{c}\text { Clinical harm very } \\ \text { months, but unlikely }\end{array} & \begin{array}{c}\text { likely if postponed } \\ \text { more than six weeks }\end{array} \text { to have presented via A\&E } \\ & \begin{array}{c}\text { despite the current pandemic } \\ \end{array} & \end{array}$

A\&E = Accident and Emergency Department.

\section{LOCAL CHANGES}

At the Department of Surgery in Sultan Qaboos University Hospital, Muscat, Oman, certain changes were adopted resulting in a reduction of outpatient department (OPD) patients and elective operating theater (OT) cases by $70 \%$ and $100 \%$, respectively. All booked cases in OPD were triaged by consultants at least a week earlier while non-urgent cases were given new dates and stable follow-up patients were given refill prescriptions. The hospital adopted an effective policy that allowed patients to refill their medications by sending a WhatsApp (Facebook Inc., Menlo Park, California, USA) message with their medical record number and the name of the clinic without having to attend the OPD. This policy helped to avoid crowding of the OPD areas. The emergency and oncology cases remained largely unaffected with a monthly average of 18 and 10 cases, respectively. However, the number of COVID-19 positive cases who underwent operations is not known mainly because screening of patients who were scheduled for surgery and were asymptomatic or at risk of COVID-19 had not yet been implemented. Other implementations included: (1) training of staff on the use of personal protective equipment; (2) enforcing the OT guidelines to categorise patients into emergency, oncological and non-oncological urgent cases with the allocation of a COVID-19 OT room; and (3) starting online teaching for medical students at different levels using Zoom (Zoom, San Jose, USA), where the tutor joins the students in live interactive sessions. The Oman Urology Society (OUS) also implemented actions to deal with the COVID-19 pandemic. All society members were kept updated 
about local and international guidelines related to COVID-19 and were informed of webinars to update their knowledge. The $2^{\text {nd }}$ OUS international conference, in collaboration with the Arab Association of Urology to be held on 1-3 October 2020, was converted to a virtual conference in view of the increasing COVID-19 cases in the region. On an individual basis, members were involved in remote patient consultations through telephone, WhatsApp (Facebook Inc.) or email communications. OUS is supporting the activities of the Oman Medical Association in dealing with the COVID-19 pandemic.

\section{POST-COVID-19 ERA}

It is now clear that this pandemic will last several months until effective vaccination or definitive treatment becomes available. In order to overcome this and future pandemics, virtual healthcare solutions need to be introduced, such as telemedicine with applications including tele-consultation, tele-education and tele-research. Tele-consultation entails connecting with the patients by audio and video (e-visits) with an interactive medical consultation. This can be conducted using several softwares such as Zoom (Zoom, San Jose, California, USA), Gotomeeting (LogMeIn Inc., Boston, Massachusetts, USA), Skype (Facebook Inc.), Facetime (Facebook Inc.), Google Meet (Google, Mountain View, California, USA) and Microsoft Team (Microsoft, Redmond, Washington, USA).

The concept of telemedicine in Oman has been explored and implemented with limitations in select hospitals and specialties such as teleradiology. However, it is not widely used in Oman mainly due to legal issues, high cost, technical complexity as well as a lack of current local regulatory requirements such as the Health Insurance Portability and Accountability Act in the USA. If properly adopted, telemedicine can help patients during pandemics such as COVID-19, when access to the healthcare system has been limited, as well as during routine normal life situations to compensate for hospital-bed shortages and the lack of some medical specialists in remote areas of the country. Tele-consultation could be a useful system to physicians who are inspecting medical data of patients located in remote areas that may be performed either in real-time or asynchronously. An effective telemedicine system has unique requirements such as a telemedicine workstation, communication network, human perception of media and telemedicine security. ${ }^{5}$ Physicians should adhere to the applicable laws governing the practice of telemedicine as set by organisations such as The American Medical Association. ${ }^{6}$ Recently, the Omani Ministry of Health has circulated guidelines to regulate the practice of telemedicine in Oman and some government and private hospital have started to implement them.

Mohamed S. Al-Marhoon

Department of Surgery, Sultan Qaboos University, Muscat, Oman

E-mails:msalmarhoon@gmail.com and mmarhoon@squ.edu.om

\section{References}

1. Maginn W. COVID-19 what-you-need-to-know. From: www.warrenmaginn.com/environment/caronavirus-what-you-need-to-know Accessed: Jul 2020

2. World Health Organization. WHO Coronavirus Disease (COVID-19). From https://covid19.who.int Accessed: Oct 2020.

3. European Association of Urology Guidelines. 2020 Edition. Arnhem, The Netherlands: European Association of Urology Guidelines Office; 2020. https://uroweb.org/guidelines.

4. Ribal MJ, Cornford P, Briganti A, Knoll T, Gravas S, Babjuk M, et al. European Association of Urology Guidelines Office Rapid Reaction Group: An Organisation-wide Collaborative Effort to Adapt the European Association of Urology Guidelines Recommendations to the Coronavirus Disease 2019 Era. Eur Urol 2020; 78: 21-8. https://doi.org/10.1016/j.eururo.2020.04.056.

5. Altaei MH, Abdul-Mehdi ZT. Telemedicine Requirements for Treatment Network in Oman. J Adv Comput Netw 2013; 1: 246-9. https:// doi.org/10.7763/JACN.2013.V1.49.

6. Chaet D, Clearfield R, Sabin JE, Skimming K, Council on Ethical and Judicial Affairs American Medical Association. Ethical practice in Telehealth and Telemedicine. J Gen Intern Med 2017; 32:1136-40. https://doi.org/10.1007/s11606-017-4082-2. 